\title{
La sexualidad femenina en el cine de Lars von Trier. Caso concreto: Antichrist (2009).
}

\begin{abstract}
Sofía Otero Escudero
Universidad de Sevilla, España

Resumen

http://dx.doi.org/10.12795/AdMIRA.2018.01.03

En el marco de una modalidad de trabajo que vincula investigación científica y análisis práctico, se realiza un rastreo y revisión bibliográfica sobre la representación de la sexualidad femenina en el cine, con la teoría fílmica feminista como pilar fundamental. En concreto, se analiza la representación de dicho concepto en la película Antichrist (2009) de Lars von Trier, seleccionada como estudio de caso sobre la representación y análisis de su filmografía contemporánea.

A través de un análisis conceptual teniendo como foco de investigación la evolución del personaje femenino y su sexualidad, la investigadora intentará concluir una breve reflexión sobre la representación que el director danés hace sobre la misma en su filmografía de la última década.
\end{abstract}

\section{Palabras clave}

Lars von Trier, sexo, sexualidad, mujer, femenina/o, naturaleza, cinematografía, teoría fílmica feminista.

\begin{abstract}
In the context of a work modality that links scientific research and practical analysis, it is developed a bibliographic review about the female's sexuality on the cinema, with the Feminist Film Theory such key pillar of the selected papers. In this particular case, it is selected Antichrist (2009) by Lars von Trier as a case study about female sexuality's representation within his contemporary filmography.

By means of a conceptual analysis with the female character evolution and her sexuality as the focus of research, the researcher would try to conclude a brief comment about the depiction of the women's sexuality, by the Danish director in his last decade's filmography.
\end{abstract}

\section{KEYWORDS}

Lars von Trier, sex, sexuality, woman, female, nature, cinematography, Feminist Film Theory. 
Esta idea de la imagen como arma que detiene el paso del tiempo y devalúa la realidad me hace sentir muy incómoda. Si Occidente tiene en sus manos este poder de controlar el tiempo a través de las imágenes, ¿qué somos si no controlamos nuestra imagen? ¿Quién soy yo y quién elabora mi imagen? (...)

(Fatema Mernissi 2000)

\section{Introducción}

Sigmund Freud hacía referencia en su psicoanálisis a la construcción del "yo" como el equilibrio entre el "ello" - fondo de pulsiones y deseos - y el "superyó" - mandatos o prohibiciones de la sociedad en la que vivimos -, y relacionaba esta construcción con la sublimación de esos deseos reprimidos por la sociedad a través de un canal diferente como puede ser la cultura y el arte. No obstante, así como en el surrealismo la sublimación era real, en el posmodernismo esa sublimación ha dado lugar a una desublimación represiva en la que los deseos, en concreto sexuales, se representan de forma muy explícita y se convierten en fetiche, dando lugar a una represión aun mayor de los deseos sexuales. “Aquí, lo interesante de la sublimación cultural no es su sustitución de un fin sexual por otro no sexual, sino las potencialidades y la plasticidad de la pulsión sexual” (Marín, 2014:23). Esa cultura a la que hacía referencia Sigmund Freud tiene su mayor apogeo en el ámbito cinematográfico, en el cual se ha representado desde tiempos remotos la sexualidad y el deseo. No obstante, la sexualidad femenina siempre se ha representado en torno a un heteropatriarcado en el que la mujer no es más que un objeto de deseo y es precisamente por eso por lo que las propias teorías fílmicas feministas cuestionaron el psicoanálisis del mismo Sigmund Freud.

\footnotetext{
Producto de una sociedad burguesa, capitalista y sexista, la magia del cine, sea del de Hollywood en tanto discurso dominante, sea del de todo el cine que cayó en su esfera de influencia, se basa en la manipulación del placer visual, en la codificación de 'lo erótico en el lenguaje del orden patriarcal' mediante la sustancialización e identificación de lo femenino como to - be - looked - at - Ness: objeto erótico por excelencia, cuerpo aislado, embellecido, exhibido, a la espera del desenlace final. (Colaizzi, 2003:340).
}

Actualmente, la visión sobre la sexualidad femenina ha ido cambiando gracias al trabajo de muchas mujeres e incluso hombres que a través de sus tratados y la esencial "Teoría Fílmica Feminista" han conseguido ir cambiando el imaginario colectivo. No obstante, el cine no deja de ser uno de los mayores referentes de reflejo social de la cultura, y el cambio de visión en este ámbito parece aún mucho más alejado de la realidad. "Las tecnologías de género, un complejo de prácticas sociales entre las que de Lauretis incluye el cine, producen las relaciones 
imaginarias denominadas "hombre" o "mujer" entre los individuos y sus condiciones reales de vida" (Sainz Pezonaga, 2017:2).

En este sentido, tal y como afirma Laura Mulvey (1975), la pantalla del cine funciona como un espejo de la sociedad, no solo en el que nos vemos reflejados sino que yendo más allá nos muestra cómo debemos ser y cómo debería de ser nuestra imagen (837). Por otra parte, la mujer como actante en la narrativa fílmica, se suele representar como pasiva frente al hombre como actante activo. Esto provoca que las tramas de las películas sean dirigidas por los hombres, y sobre todo, que las imágenes relacionadas con la sexualidad femenina no aporten nada al avance de la trama, sino que sirvan como mero complemento estético de la secuencia fílmica; o incluso que el deseo de la mujer resida en satisfacer a un hombre, y no un deseo hacia su propia satisfacción.

Como elemento añadido a estos rasgos, el placer en la narrativa de una película reside exclusivamente en el hombre y en la generación de dicho placer de la mujer hacia este. Es difícil encontrar películas en las que lo que se busque sea el placer de ella. Cuando es representado dicho placer en alguna cinta fílmica es con una estética erótica, alejada de la naturalidad y autenticidad de la sexualidad femenina. Junto a esto, habría que destacar el hecho del enigma que envuelve a la mujer y su sexualidad, tal y como bien explica Laura Mulvey en su capítulo Pandora: topografías de la máscara y de la curiosidad en Colaizzi (1995). Aquí, Mulvey hace una comparativa de lo más interesante entre la representación de la mujer y el mito de Pandora y añade una cita de Ludmilla Jordanova:

El velo significa secreto. Los cuerpos de las mujeres y, por extensión, los atributos femeninos, no pueden ser tratados como totalmente públicos, ya que algo peligroso puede suceder, los secretos pueden ser descubiertos si se muestran a la vista. Pero al convertirlos en algo tan inaccesible y peligroso, se formula una invitación a conocer y a poseer. El secreto asociado con los cuerpos de las mujeres es sexual y está relacionado con las múltiples asociaciones entre la mujer y lo privado (Mulvey, 1995:70).

Esta invitación a poseer y conocer a la que hace referencia Jordanova es lo que se podría relacionar con las numerosas causas de abusos sexuales en la actualidad de hombres hacia mujeres. Ya en el 2014 las cifras eran escalofriantes ${ }^{1}$.

En concreto, es curioso reseñar cómo un estudio de 2017 concluye que del alto número de abusos sexuales y físicos detectados en Europa, Dinamarca tuvo la cifra más alta, albergando

\footnotetext{
1 "En la Unión Europea viven 62 millones de mujeres que han sufrido violencia física o sexual, otros 62 millones la han padecido durante la infancia; 100 millones han sido acosadas sexualmente, 80 han sufrido violencia psicológica y 10 millones han sido privadas de su libertad, incluso dentro de sus propias casas". (Eldiario.es., 2014).
} 
un 52\% de las mujeres afectadas (Senthilingam, 2017); lugar originario del director de cine Lars von Trier, que será objeto de estudio posteriormente.

Volviendo así al cine, algunas películas como pueden ser Pretty Woman (Garry Marshall, 1990) o Tesis (Alejandro Amenábar, 1996) en las que la mujer puede ser la aparente protagonista, finalmente solo es protagonista su imagen y figura como mujer y como víctima, pero el avance de la trama sigue llevándolo el hombre. "Por esto, desde una perspectiva antropológica, algunos estudios han llegado a la conclusión tácita de que el poder masculino se ha basado cíclicamente en el control de la sexualidad femenina" (Febrer Fernández, 2014:214). Incluso yendo más allá, aquellas en las que la mujer avanza la trama, son aquellas en las que la figura de la mujer está "machificada”, como puede ser Resident Evil, Tom Raider o Alien.

Tradicionalmente, la mujer exhibida ha funcionado en dos niveles: como objeto erótico para los personajes de la historia que se desarrolla en la pantalla, y como objeto erótico para el espectador en la sala, con una tensión movediza entre las miradas que se despliegan a cada lado de la pantalla. (Mulvey, 1975:838). ${ }^{2}$

Por otro lado, es interesante analizar el aspecto visual de las películas, dado que los planos en los que aparecen mujeres suelen fragmentar el cuerpo de la misma con primeros planos y planos detalle, además de mostrar imágenes muy estéticas generando una situación erótica y sensual en torno a ella. Respecto a este ámbito hay que tener en cuenta que las películas son muy visuales, por lo tanto, lo primero que el espectador va a registrar en su memoria no es la historia en sí, sino las imágenes. ¿Qué ocurre entonces cuando estas son demasiado explícitas, e incluso desagradables? O todo lo contrario, cuando las imágenes son demasiado estéticas e incluso irreales. El tema de la sexualidad es difícil de abordar a través de las imágenes, sobre todo sin llegar a entrar en el ámbito de lo pornográfico. En el siglo XXI, la libertad de expresión y de creación está en auge y hay miles de imágenes viajando a través del mundo; y esa globalización de las mismas debería de funcionar tanto para la consolidación de la cultura, como para la oposición y transgresión a la misma.

Es bien sabido que el audiovisual es una de las mejores herramientas de representación de las transformaciones y cambios sociales. $\mathrm{Y}$ en ese sentido es, sin duda, un medio único también como dinamizador de transformación cultural por la igualdad y una herramienta básica de visibilidad de todas aquellas identidades reprimidas y ocultadas. (Zurian Hernández, 2011:7).

El cine tiene muchísimo peso y responsabilidad a la hora de eliminar los estereotipos y las ideas tradicionales sobre la sexualidad de la mujer, la cual funciona en este contexto como objeto de

${ }^{2}$ Traducción extraída de: http://www.estudiosonline.net/est_mod/mulvey2.pdf 
deseo sin poder ser el motor de una trama y por supuesto sin poder mostrar su placer sexual como mujer, sino como objeto o sujeto placentero para el hombre. De esta forma, tal y como afirman Gila y Guil (1999), el cine genera una serie de modelos que influyen a la hora de crear las identidades aceptadas o no socialmente. "El cine contribuye a la formación, mantenimiento o eliminación de estereotipos, según apoyen o no las creencias aceptadas socialmente. Además, genera modelos que influyen en la creación de la identidad social”. (Gila \& Guil, 1999:89).

Finalmente, dado este contexto sociológico que acontece aun en el siglo XXI, vemos relevante analizar en profundidad el cine de un director como Lars von Trier (la última década) el cual habla sobre el tema de la sexualidad en la mayoría de sus películas y no está ajeno a la polémica."La influencia del cine es tan poderosa que se ha llegado a decir que es éste el que crea los personajes que luego se desarrollan en la vida real y no a la inversa". (Gila \& Guil, 1999:92).

\section{Orígenes de la teoría fílmica feminista}

En primer lugar habría que reseñar el hecho de que muchas directoras de cine hayan estado en la sombra. Una de las primeras que inició el trabajo de las mismas en la cinematografía fue Alice Guy Blaché. "Ella fue una de las primeras en ver el potencial del invento de los hermanos Lumière para fundir imágenes en pantalla (...), quizás ella fue la primera persona en usar las imágenes en movimiento para contar una historia" (Smith, 1975: 2) ${ }^{3}$.

No obstante, es desde los años 70 cuando se empiezan a desarrollar en profundidad una serie de teorías y estudios de género que tal y como afirman Zurian Hernández y Herrero Jiménez en su artículo, fueron unos estudios “(...) cuya principal aportación ha sido la ruptura de fronteras entre géneros y sexualidades impuestas por la tradición heteropatriarcal en la que se basa el imaginario audiovisual occidental" (2014: 9).

Abordaron el tema del poder patriarcal sobre la mujer en la sociedad y aportaron un marco teórico esencial para las investigaciones en torno a la cinematografía y la representación de la mujer en la misma, dando lugar a la teoría fílmica feminista.

Esta teoría tenía como foco principal, tal y como coinciden en afirmar todas las teóricas, "hacer visible lo invisible". "Comienza su andadura con el objetivo común de analizar películas existentes (...), y dirige su atención a ciertos aspectos de ellas que con frecuencia pasan inadvertidos". (Kuhn, 1991: 87).

\footnotetext{
${ }^{3}$ Traducción por parte de la autora.
} 
En este sentido, el feminismo, tal y como desarrolla Annette Kuhn (1991) en su libro, tiene dos posibles vertientes. Una perspectiva más teórica como posición ideológica y marco de referencia, y otra más metodológica que da lugar a herramientas conceptuales. Ante esto, la teoría fílmica feminista se inclina más por la segunda opción y adopta las metodologías desarrolladas fuera de la esfera del feminismo, inspirándose en un análisis sociológico de producción cultural, en estudios sobre la cultura y en la teoría del cine.

Respecto a las bases y el desarrollo del marco teórico, Palencia Villa y Palencia Villa (2014) hablan sobre el uso de la lingüística, la sociología, la semiótica y el psicoanálisis. Algo que Kuhn (1991) y Zurian Hernández y Herrero Jiménez (2014), coinciden en acotar en el uso e influencia del psicoanálisis, el estructuralismo y la semiótica en las fases más tardías de la teoría. En este sentido, el desarrollo de la teoría fílmica feminista no fue homogéneo, por lo que se podrían bifurcar dos líneas de investigación, una de orden sociológico - la presencia de la mujer en la producción cinematográfica desde el punto de vista historiográfico -, y otra desde el orden teórico - profundizando en los estereotipos -. (Guarinos, 2014: 93).

A principios de los años 70, la teoría fílmica feminista bebió de diversas teorías y estudios culturales, no sólo del feminismo, teniendo también una relación inevitable con la política.

Una segunda fase de estos incipientes estudios, muy influida por la semiótica y el psiconálisis, de influencia freudiana y lacaniana, instaura la etapa de mirada - poder. Las revistas Screen y Camera Obscura jugaron un papel importante en Inglaterra y EEUU en la difusión de una crítica a la búsqueda de la deconstrucción. (Guarinos, 2014: 93).

Giulia Colaizzi (1995) afirma que lo que se busca en esta segunda fase es cambiar los modos de estructurar la mirada en la tecnología, la cual cambia la forma de ver y percibir, modificando a su vez la imagen fílmica y eliminar esa idea del cine como aparato ideológico, es decir, deconstruir lo que conecta al espectador con la pantalla.

Durante esta década, "surgen los grupos interdisciplinarios de mujeres, en donde teóricas trabajaban conjuntamente con artistas o activistas feministas, se crean festivales de cine de mujeres como el New York International Festival of Women's Film”. (Castro Ricalde, 2002: 25). Entre las teóricas más destacadas está Laura Mulvey, la cuál publica el ensayo "Placer visual y cine narrativo", que se convertirá en una de las piedras angulares de la teoría fílmica feminista, tal y como recoge Colaizzi en su libro, añadiendo que Mulvey:

(...) sienta las bases y las coordenadas para el debate teórico de la siguiente década; plantea problemas que serán centrales para el feminismo y para la teoría fílmica: la cuestión del placer de las mujeres y las que se refieren a la recepción fílmica y al lugar espectatorial. (Colaizzi, 1995:23). 
En dicho ensayo, Laura Mulvey (1975) pone el énfasis en la cultura patriarcal y el orden simbólico que aprisiona a la mujer para que el hombre pueda vivir sus fantasías y deseos sexuales, tanto en lo estético como en lo narrativo. En este sentido presenta dos tipos de miradas y placeres contra las que hay que luchar en el cine, la "escoptofilia" que consiste según Freud en tratar a las personas como objetos a través de una mirada controladora. "La posición del espectador en el cine es evidentemente una posición de represión de su exhibicionismo y de proyección en el intérprete del deseo reprimido"4. (Mulvey, 1975: 835). Y por otro lado está el narcisismo y el ego del "yo" en la pantalla y la identificación con la imagen visual.

Por lo tanto hay distintas formar de representar a la mujer en el cine y como consecuencia, de abordar su estudio. Una de las más relevantes para nuestra investigación es la mujer como actante (pasiva/activa) y la mirada del espectador que recae sobre ella.

Actualmente, con teóricas como Judith Butler, la teoría fílmica feminista sigue evolucionando y creciendo hacia otras vías y ámbitos como puede ser el sector LGTBI o Queer. Una de las teorías que la estudiosa feminista Butler ha desarrollado ha sido la performatividad de género, haciendo referencia a lo esencial de la presente investigación que consiste en la creación cultural y social de ciertos roles que no residen en la biología o naturaleza de las personas, sino que son construcciones. "En este sentido, y en la línea foucaultiana, puede entenderse la performatividad del lenguaje como una tecnología; como un dispositivo de poder social y político". (Duque, 2010:87).

Por lo tanto, tal y como afirma Martínez Salanova (2016), hoy en día siguen existiendo dos categorías de películas, aquellas en las que los roles tradicionales de la mujer y estereotipos basados en ideales patriarcales se siguen perpetuando, y por otro lado las películas que contribuyen al cambio social mostrando otra visión más crítica en la que la mujer va tomando una mayor importancia.

\section{El cine de Lars von Trier}

Lars Trier, hijo de Inger Host y Ulf Trier, nació en Dinamarca el 30 de abril de 1956 en Lundtofte, al norte de Copenhague. Lars fue un niño bastante problemático desde pequeño en el colegio, dado que destacaba por cuestionar todo lo que sus profesores le enseñaban e ir en una línea más ajena y radical a los demás, en todos los sentidos. Ya desde niño tenía clara su vocación por el cine, aunque comenzó incluso siendo actor de sus propios cortometrajes.

\footnotetext{
${ }^{4}$ Traducción por parte de la autora.
} 
Lars von Trier ya en sus primeros cortometrajes manifestó su preferencia por la representación de caracteres femeninos. Sobre todo, aquellos que propician una reacción en los personajes masculinos. caracteres femeninos dominantes y manipuladores, capaces de desencadenar una respuesta violenta en los otros. (Díaz Lucena, 2015: 160).

Stevenson (2005) explica que en la Universidad crearon el grupo Film Group 16, donde se reunían para discutir el tema de las películas que se iban a rodar, etc. con la diferencia de que Lars nunca dejaba que sus películas fueran objetivo de discusión, tuvo siempre las ideas muy claras. Ya desde este momento, rodaron dos de sus primeras películas, en la misma línea que sus películas actuales. La primera en 1977 fue El jardín de orquídeas, basado en un jardinero (judío), que se disfrazaba o de mujer o nazi para acostarse con el amor de su vida, pero termina abusando de una niña pequeña para saciar sus deseos sexuales. La siguiente fue Menthe - La feliz en 1979, basada en una relación sadomasoquista entre dos mujeres, enlazando también deseos sexuales e ideologías religiosas.

Desde sus inicios Lars von Trier era un niño bastante alejado de lo común en los niños de su edad, en una línea radical y realizando unas películas basadas sobre todo en deseos sexuales aberrantes y además relacionándolo con ideas religiosas.

En este sentido, también se relaciona todo con una característica que suele aparecer en todas sus películas; la culpabilidad de la mujer y la naturaleza corrupta del ser humano. "En la mayoría de los trabajos del cineasta danés la tragedia se libera por medio de una fuerza irracional que termina por apoderarse de los protagonistas. Esta energía parece invadirles consiguiendo que dejen de ser templados y racionales”. (Díaz Lucena, 2015: 160). En su película Antichrist (2009), una de las más polémicas, trata precisamente la naturaleza maligna de los seres humanos centrada en los deseos sexuales y sobre todo en la culpabilidad de la mujer, en este caso por la muerte de su hijo.

En definitiva, el tema de la culpa, la naturaleza aberrante del ser humano y el sexo - con tintes religiosos incluso - son algo permanente en los guiones de Lars von Trier.

Además, siempre de forma polémica y controversial con imágenes de sexo y órganos genitales explícitos y donde se lleva el comportamiento del ser humano al límite (sobre todo de las mujeres).

\section{Análisis práctico.}

Para analizar la película seleccionada del director de cine danés Lars von Trier se han tenido en cuenta distintas categorías de diversos artículos científicos, junto al propio criterio de la investigadora desde la teoría desarrollada anteriormente. 
El foco de análisis se centrará en la evolución del personaje femenino y su sexualidad - se evitará incluir cualquier característica de la mujer observada en el film que no esté relacionada con el sexo -. Por lo tanto lo primero será detectar si la figura de la mujer es protagonista y relevante en la historia o secundaria. Una vez reseñado esto, dentro de la evolución del personaje se utilizarán las siguientes ideas o conceptos, utilizados en su mayoría para representar a las mujeres en la cinematografía y desarrollados por teorías y estudios de filmografía feminista. Estos nos servirán como filtro para detectar cómo Lars von Trier representa a las mujeres en la película seleccionada:

- Canon de belleza: definiciones normativas de feminidad. Dentro de las definiciones se tendrá en cuenta el vello púbico, la complexión corporal, etc. ${ }^{5}$ En estos cánones de belleza habrá que prestar especial atención al cuerpo desnudo de la mujer. ${ }^{6}$

- Sexo: es interesante analizar cómo se representan los genitales femeninos en las películas ${ }^{7}$. Además, el tipo de relaciones sexuales (heterosexuales, homosexuales, sadomasoquistas, etc.), junto a las posibles masturbaciones de la mujer ${ }^{8}$. Por otra parte, respecto a las relaciones sexuales, hay que analizar la evolución de las mismas y las consecuencias de que la mujer lleve a cabo dichas relaciones.

- Sexualidad y placer vs. maternidad ${ }^{9}$.

- Negación y patologización de la sexualidad: la excitación femenina considerada como sinónimo de enfermedad ${ }^{10}$.

- Única forma de gratificación sexual: negación del orgasmo femenino. ${ }^{11}$

- Mirada del espectador: es interesante analizar lo que provoca la figura de la mujer en el espectador (hombre), si realmente la figura de la mujer se representa para ser observada (la mirada del espectador coincide con la mirada de la cámara) o no. Además, habría que destacar si esa mirada produce placer en el espectador o también angustia y desagrado $^{12}$.

\footnotetext{
${ }^{5}$ Cuando se hace referencia a las definiciones normativas de feminidad, se suele tener en cuenta a la hora de representar el cuerpo de la mujer desnuda: la frontalidad, el detenimiento del cuerpo de ella, la eliminación del vello y la mirada complaciente de ella hacia el espectador. (Garro Larrañaga, 2011: 310, 312).

${ }^{6}$ Idea muy relevante recogida en Garro Larrañaga (2011:310) sobre el cuerpo-placentero que pueda subvertir los códigos establecidos.

${ }^{7}$ Hay una falta de información y especificidad de las corporalidades femeninas y su sexualidad en las películas de ideas tradicionales y androcéntricas. (Olivia Barboza, 2017: 186).

${ }^{8}$ El adoctrinamiento del cuerpo femenino, su objetivización y patologización. (Oliva Barboza, P., 2017, p.165).

${ }^{9}$ Idea desarrollada por Olivia Barboza, (2017) en la p.184, donde habla de la sexualidad unida al trabajo (prostitución) y la sexualidad unida a la maternidad como únicas posibles vías desarrolladas desde los ideales tradicionales y heteropatriarcales.

10 (Olivia Barboza, 2017: 82).

11 (Olivia Barboza, 2017: 183).

12 (Sainz Pezonaga, 2017: 3-5).
} 
- Personaje masculino conduciendo la historia: habrá que observar quién es realmente el o la conductor/a de la trama, en este caso además, prestando especial atención a quién o qué controla el deseo y la sexualidad de la mujer.

- Polaridad activa/masculina; pasiva/femenina. ${ }^{13}$

- Aparición de la violencia.

- Rol de la mujer relacionado con: pasividad, afectividad, cuerpo, naturaleza, dominio de sentimientos, capacidad de cuidar a los demás, inestabilidad y el ámbito privado ${ }^{14}$.

\subsection{Caso de estudio: Antichrist (2009).}

Lars von Trier tiene en todas películas una serie de características comunes, siendo la película Antichrist un conglomerado de todas ellas llevadas al extremo. En general, todos sus films coinciden en representar a la mujer como protagonista, con todos sus roles de inestabilidad, maternidad, histeria, etc., con una obsesión casi enfermiza por la naturaleza, la religión y el sexo. Las películas más representativas junto a esta son Nymphomaniac Vol I. y II., y Dogville.

Centrándonos en Antichrist, habría que destacar que ya desde el principio se hace alusión al tema central que conglomera todo lo demás cuando en los créditos iniciales se escribe la palabra "Antichrist" siendo la "t" final representada con el símbolo de la mujer.

Este film cuenta la experiencia de un matrimonio que pierde a su hijo al morir por accidente tras caerse por la ventana. Tanto la mujer como el hombre son los protagonistas aunque ella parece serlo más que él por el tema predominante que es su mente y sus sentimientos. No obstante, la trama la conduce su marido todo el tiempo y cuando no es él el que la conduce a ella, es su naturaleza, siendo por lo tanto ella expropiada de todo tipo de capacidad de toma de decisiones y cumpliéndose así la polaridad pasiva -mujer / activa - hombre señalada por Garro Larrañaga (2011).

Respecto al canon de belleza de la mujer protagonista es morena con el pelo largo, delgada y con los pechos pequeños. Teniendo en cuenta la clasificación de Garro Larrañaga (2011), la aparición del vello púbico de ella rompería con la normativa androcéntrica definida. Respecto a la frontalidad, en ningún momento se ve el cuerpo de ella desnudo al completo y en el único momento en el que se ve (fragmentado) está de espaldas. Además, es interesante observar que

13 (Garro Larrañaga, 2011: 310).

14 (Gila y Guil, 1999: 68). 
cuando se le ve de cuerpo entero, sólo está desnuda de cintura para abajo, excepto cuando ella se masturba, que se le ve lateralmente.

En relación con lo comentado en este punto, hay dos escenas claves en los que la mirada hacia ella -por parte de su marido que además la está viendo desnuda- y de ella hacia él, es complaciente. De forma consecutiva al plano de la mirada de él, aparece el plano de ella desnuda convirtiéndose así la mirada de la cámara en la mirada del espectador.

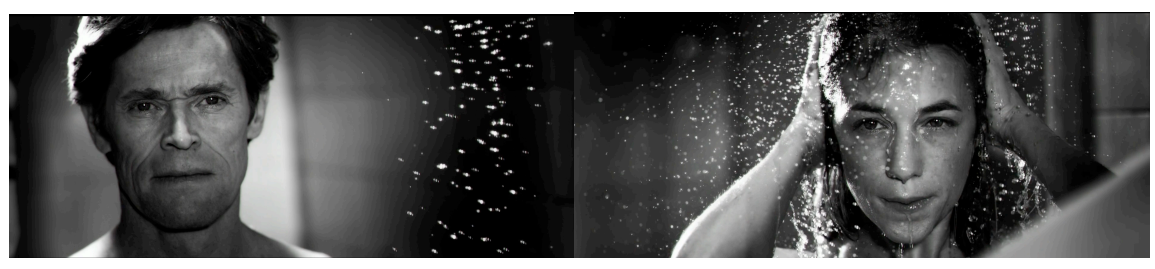

Fotogramas recuperados de Antichrist de Lars von Trier.

La primera escena de sexo y la más explícita se representa de forma estética acompañándola con música y en blanco y negro. Una de las veces que se muestra el acto sexual es con un primer plano de los órganos sexuales de ambos. Según la clasificación de Olivia Barboza. (2017), el punto más representativo en este film de Lars von Trier sería el de la sexualidad y el placer vs. la maternidad. Todo el argumento de fondo de la película se basa en la idea de la muerte del hijo por culpa de la madre, por no saber cuidar del niño y además por estar teniendo placer mientras que no le prestaba atención. Los primeros planos, totalmente simbólicos y clarificantes, muestran las relaciones sexuales de la pareja mientras el hijo (Nick) se dirige hacia la ventana. Se intercalan imágenes de placer de ella con imágenes del niño preparándose para asomarse a la ventana y caerse, siendo el plano clave cuando ella llega al clímax mientras él va cayendo para terminar muriendo.

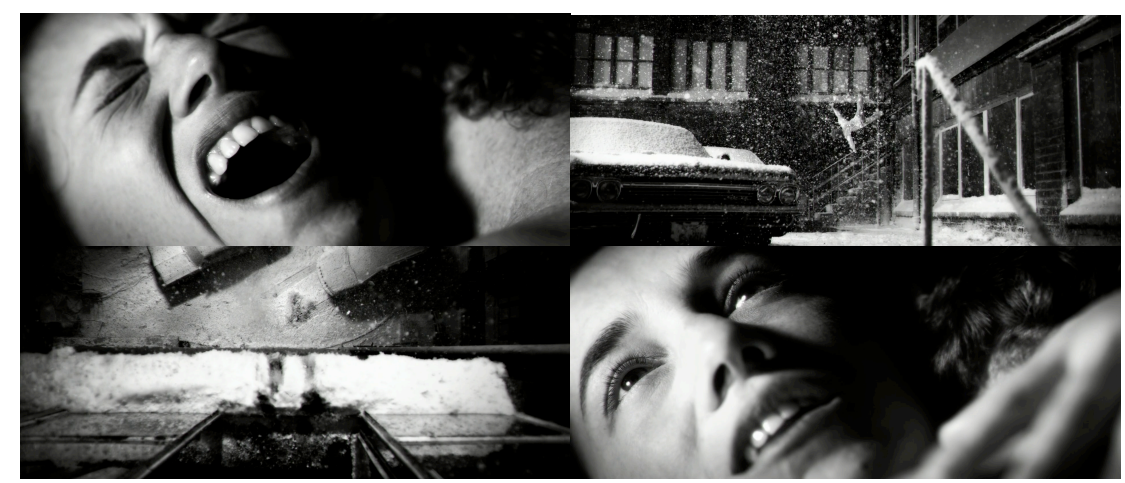

Fotogramas recuperados de Antichrist de Lars von Trier.

A lo largo de la película, la simbología y las metáforas de la maternidad - que se ve truncada por la búsqueda del placer -, se van sucediendo. Además, se descubre al final del film que ella 
le ponía los zapatos a su hijo al revés, como un tipo de inestabilidad mental (relacionada con su naturaleza primitiva y sexual) que le hacía incapaz de cuidar bien de su hijo y por lo tanto era algo aberrante en una mujer, tal y como se presenta en Gila \& Guil (1999), al hablar del rol de la mujer que tiene la capacidad de cuidar a los demás.

En todo momento, es ella la que le busca a él para tener relaciones sexuales, cuando se siente mal, cuando está triste, cuando está enfadada, en todo momento como una "cura" a sus males. Cuando él no le corresponde ella responde con violencia y conforme va avanzando la película sobre todo cuando se trasladan a una cabaña en el bosque -, la evolución de las relaciones sexuales es decadente, siendo cada vez más peligrosas y siendo ella cada vez más inestable. Esto enlazaría con la idea de la patologización de la sexualidad de ella, dado que termina por ser una enfermedad que destruye a ambos, y la acaba matando a ella.

En una de la escenas que ella busca su placer, le pide al marido que la golpee para poder soportar el dolor que siente por la pérdida de su hijo, necesita un sexo violento en el que sufra como castigo de lo que le ha pasado a su hijo y por lo que ella se siente culpable -, cuando él se niega, ella se masturba en la naturaleza. Se ve cómo ella se masturba para llegar al orgasmo hasta que finalmente él cede y se observa un plano del cuerpo de él sobre el de ella (la espalda de él).

Finalmente, ella le golpea a él en su órgano sexual e intenta matarle porque ella dice: "Cuando los tres mendigos llega, alguien debe morir”, como castigo, para redimir la culpa. Así, ella se amputa su clítoris -negación del orgasmo femenino (Olivia Barboza, 2017)- , mostrando Lars von Trier que realmente es el placer de ella el que mató a su hijo y representándolo de forma explícita para el espectador. Es la destrucción y el caos total desencadenado por la naturaleza interior, la de ella, su "yo" más primitivo. De hecho, el marido - psicólogo -, intenta durante toda la película encontrar cuál es el mayor miedo o enemigo de la mujer, pasando desde el bosque hasta Satán y concluyendo que en realidad su mayor enemigo es ella misma. No obstante, al final es el marido el que la mata a ella, la estrangula y como mayor símbolo, él la quema en una hoguera, como se hacía con las "brujas". En la escena final, todas las mujeres que han sido asesinadas ( $\sin$ rostros) pasean por la naturaleza alrededor de él, metáfora de la naturaleza de todas las mujeres.

Una de las categorías de Gila \& Guil (1999), más reseñable en este film del director danés es la de la naturaleza. Toda la película es una gran simbología de la naturaleza - tanto interior como exterior -, y la relación de la mujer con ella. Además, se nombra constantemente a la naturaleza 
como el Edén, haciendo así referencia a la religión que el director tanto tienen en cuenta en su filmografía. De hecho, en una de las escenas, ella le dice al marido que "la naturaleza es la Iglesia de Satán”. (Antichrist, 2009). Una de las escenas claves desarrolla esta conversación:

¿Qué quieres señor naturaleza? Herirte todo lo que pueda, matándote. Estoy fuera, pero también dentro, la naturaleza del ser humano. Esa naturaleza humana que lleva a la gente a hacer cosas horribles contra las mujeres. Esa naturaleza me interesa mucho, es el objeto de mi tesis. No se debe subestimar el Edén. Si la naturaleza humana es diabólica, también lo es la de las mujeres. Las mujeres no controlan su propio cuerpo, la naturaleza es la que los controla. Hiciste tu tesis para estudiar las cosas horribles que se hicieron en contra de las mujeres ¿pero lo has terminado entendiendo como una prueba del demonio de las mujeres? (Antichrist, 2009).

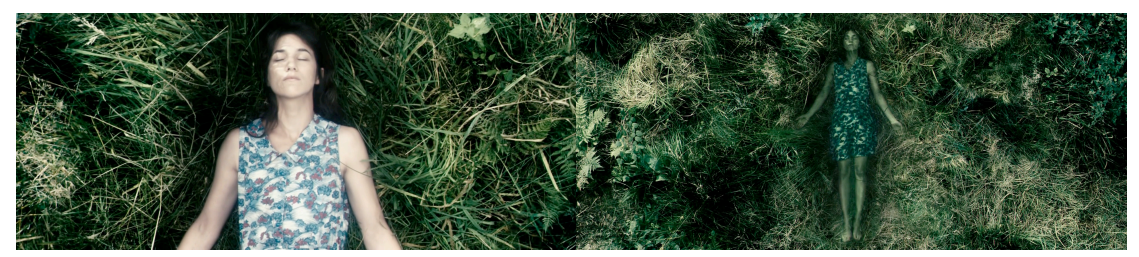

Fotogramas recuperados de Antichrist de Lars von Trier.

\section{Conclusiones}

Tras la revisión bibliográfica, podríamos inferir que la representación de la mujer en el cine no ha sido favorable en su mayoría para el colectivo de la mujer, dado que ha predominado siempre el placer del hombre que mira a la mujer y es él el que disfruta con la sexualidad de ella y no ella misma. Además, siempre se ha mirado a la mujer con una mirada erótica, siendo el personaje femenino un objeto sexual para el hombre y para el espectador.

En este sentido, la representación del cuerpo de la mujer y de su sexualidad en la película Antichrist del director danés, desarrolla unos códigos que difieren en muchos casos de los códigos androcéntricos establecidos. No obstante, la sexualidad y la búsqueda de placer de ella es representada como el detonante de la muerte de su hijo y las consiguientes desgracias. Es la naturaleza de la mujer - mostrada como aberrante por el director - la que la termina autodestruyendo junto al marido. De forma ejemplificada aparece esta idea al final de la película con la amputación de la sexualidad femenina como solución a todos los males, cuando la protagonista se mutila el clítoris. Además, la conducción de la trama no está realmente conducida por la mujer, dado que es su naturaleza perversa e inestable - según la representación del director - la que le hace actuar de una forma u otra.

En conclusión, Lars von Trier hace dueña de la sexualidad de la mujer a la culpabilidad y la naturaleza de la propia mujer que tal y como aparece representada parece volverse aberrante por la búsqueda de placer. Por lo tanto, se podría concluir que la representación explícita de la 
sexualidad de la mujer protagonista en la película Antichrist de Lars von Trier es simplemente un escudo estético que oculta una idea hetereopatriarcal sobre la mujer desposeída de su sexualidad y sin control sobre la misma, además del intento de la búsqueda del placer que se representa como algo antinatural y destructivo por parte de la mujer.

\section{Referencias Bibliográficas}

Antichrist. (2009). Película dirigida por Lars von Trier, Dinamarca / Alemania / Francia / Polonia / Suecia / Italia, Zentropa Entertainments [DVD].

Castro Ricalde, M. (2002). "Feminismo y teoría cinematográfica" en Escritos, Revista del Centro de Ciencias del Lenguaje. [En línea]. No.25, pp. 23-48. Disponible en: http://cdd.emakumeak.org/ficheros/0000/0532/ricalde.pdf

Colaizzi, G., (1995). Feminismo y teoría filmica. (1 ${ }^{\mathrm{a} e d .) . ~ V a l e n c i a, ~ E p i s t e m e . ~}$

Colaizzi, G. (2003). "Placer visual, política sexual y continuidad narrativa" en Arbor, CLXXIV. [En línea]. No.686, pp. 339-354. Disponible en: http://dx.doi.org/10.3989/arbor.2003.i686.644

Díaz Lucena, A. (2015). “La Diosa en Lars von Trier. La liberación de la cárcel siembra lo trágico moderno" en Trama Y Fondo: Revista De Cultura. [En línea]. No.39, pp. 159 - 172. Disponible en: https://dialnet.unirioja.es/servlet/articulo?codigo $=5681971$

Duque, C. (2010). "Judith Butler y la teoría de la performatividad de género" en Revista de Educación \& Pensamiento. [En línea]. No. 17, pp. 85 - 95. Disponible en: https://dialnet.unirioja.es/servlet/articulo? codigo $=4040396$.

Eldiario.es. (2014). "Más de la mitad de las mujeres europeas han sufrido acoso sexual" en eldiario.es. [En línea] Disponible en: http://www.eldiario.es/sociedad/millones-europeassufrido-violencia-machista_0_235177241.html

Febrer Fernández, N. (2014). "Género y sexualidad en el arte contemporáneo"en Dossiers Feministes. [En línea]. No.18, pp. 209 - 226. Disponible en: https://dialnet.unirioja.es/descarga/articulo/4941724.pdf

Filmaffinity. (s.a.). “Anticristo (2009)” en Filmaffinity. [En línea]. Disponible en: https://www.filmaffinity.com/es/film917722.html

Garro Larrañaga, O. (2011). "Aprender a mirar: la mujer como sujeto activo de la representación" en La ventana. [En línea]. No.33, pp. 302-320. Disponible en: http://148.202.18.157/sitios/publicacionesite/pperiod/laventan/ventana33/12aprender.pdf

Gila, J. y Guil, A. (1999). "La mujer actual en los medios: estereotipos cinematográficos" en Comunicar. [En línea]. No.12, pp. 89-93. Disponible en: https://dialnet.unirioja.es/servlet/articulo? codigo $=262538$ 
Guarinos, V., (2007). Mujeres en proyección. La mujer en el cine. Teoría fílmica feminista. En Loscertales, F., Nuñez, T., R.Contreras, F., Guarinos, V., Vera, T., Guerrero S., y González, R., La mirada de las mujeres en la sociedad de la información. (pp. 91-111). Madrid, Siranda Editorial.

IMDb. (s.a.). "Lars von Trier” en $I M D b$. [En línea]. Disponible en:

http://www.imdb.com/name/nm0001885/bio

Kuhn, A., (1991). Cine de mujeres. Feminismo y cine. (1 $1^{\mathrm{a} e d .) . ~ M a d r i d, ~ C a ́ t e d r a . ~ S i g n o ~ e ~}$ imagen.

Marín, T. F., (2014). Sigmund Freud: el psicoanálisis y las razones del malestar humano. Barcelona, ES: Editorial UOC. [En línea]. Disponible en: https://us.odilotk.es/opac/

Martínez Salanova Sánchez, E. (2016). "La mujer en el cine: de objeto sexual a necesaria protagonista de cambios sociales" en Aularia: Revista Digital De Comunicación. [En línea]. No.6, 1, pp. 1 -10. Disponible en: https://dialnet.unirioja.es/servlet/articulo?codigo=5350552 Mulvey, L. (1975). "Visual Pleasure and Narrative Cinema" en Screen. [En línea] No.16, 3, pp. 6-18. Disponible en: http://dx.doi.org/10.1093/screen/16.3.6

Mulvey, L., (1995). Pandora: topografías de la máscara y la curiosidad. En G.Colaizzi, Feminismo y teoría filmica ( $1^{\mathrm{a}} \mathrm{ed}$.). Valencia, Episteme S.L.

Olivia Barboza, P. (2017). "Desde lo profundo de sus obras. Un análisis sobre la patologización/expropiación del cuerpo de las mujeres" en Rev. Rupturas. [En línea], No.7, 2, $\mathrm{pp}$ 163

191.

Disponible

en:

https://investiga.uned.ac.cr/revistas/index.php/rupturas/article/view/1837

Palencia Villa, R. y Palencia Villa, M. (2014). "La representación cinematográfica en la construcción de la identidad" en Revista de estudios de género: La ventana. [En línea]. No.5, 39, pp. 62 - 96. Disponible en: https://dialnet.unirioja.es/servlet/articulo?codigo=5202509 Real Academia Española (2014). "Diccionario de la lengua española", 23. a ed.Madrid: Espasa. Disponible en: http://dle.rae.es/index.html

Sainz Pezonaga, A., (2017). "Cine e ideología de género. De Lauretis con y contra Althusser" en Demarcaciones. [En línea]. No. 5, pp. 1-17. Disponible en: http://revistademarcaciones.cl/wp-content/uploads/2017/06/SAINZ-PEZONAGA-2.pdf Senthilingam, M. (2017). "El acoso sexual está en todo el mundo: estas son las escalofriantes cifras globales", en CNN. [En línea]. Disponible en: http://cnnespanol.cnn.com/2017/11/28/elacoso-sexual-esta-en-todo-el-mundo-estasson-las-escalofriantes-cifras-globales/

Smith, S., (1975). Women who make movies (1 ${ }^{\mathrm{a} e d .) . ~ N e w ~ Y o r k, ~ H o p k i n s o n ~ a n d ~ B l a k e . ~}$

Stevenson, J., (2005). Lars von Trier ( $1^{\mathrm{a}}$ ed.). Barcelona, Paidós. 
Zurian Hernández, F. y Herrero Jiménez, B. (2014). "Los estudios de género y la teoría fílmica feminista como marco teórico y meteorológico para la investigación en cultura audiovisual" en Área Abierta. [En línea]. No. 14, 3. Disponible en: https://revistas.ucm.es/index.php/ARAB/article/view/47160/44214

Zurian Hernández, F. (2011). "Presentación: Sexualidad y políticas de género en el audiovisual" en Revista De Historia Del Cine. [En línea]. No.34, pp. 7 - 10. Disponible en: https://repositorio.uam.es/handle/10486/675222 